\title{
REFLEXOS DA CONSTITUCIONALIZAÇÃO DO DIREITO CIVIL NA FORMULAÇÃO DE UM DIREITO AO SOSSEGO APLICÁVEL NA PERSPECTIVA DO DIREITO À INTEGRIDADE FÍSICA
}

\section{Luiz Felipe Soares Aguilar ${ }^{1}$}

Resumo: Considerando o fenômeno da constitucionalização do direito civil e o conceito de direito à integridade física inserido nos direitos da personalidade, objetiva-se delinear o conceito e aplicação do direito ao sossego na perspectiva do direito à integridade física. Para tanto, procede-se ao estudo exploratório de fontes secundárias e primárias, aplicando-se aos dados obtidos o raciocínio indutivo, permitindo concluir que a atuação jurisprudencial vem focando numa aplicação do direito ao sossego marcada pela perspectiva do direito à honra, quando o estudo e conceituação do direito à integridade física permitem perfeitamente atribuir esta perspectiva à aplicação do direito ao sossego.

Palavras-chave: Constitucionalização. Direitos da personalidade. Integridade física. Direito ao sossego. Jurisprudência.

\section{REFLECTIONS OF THE CONSTITUTIONALIZATION OF CIVIL LAW IN THE FORMULATION OF A RIGHT TO QUIETNESS APPLICABLE IN THE PERSPECTIVE OF THE RIGHT TO PHYSICAL INTEGRITY}

\begin{abstract}
Considering the constitutionalization of civil law and the concept of the right to physical integrity inserted in the personality rights, it aims to delineate the concept and application of the right to quietness in the perspective of the right to physical integrity. To do so, we proceed to the exploratory study, applying to the data obtained the inductive reasoning, allowing to conclude that the jurisprudential action has focused on an application of the right to quietness marked by the perspective of the right to honor, when the study and conceptualization of the right to physical integrity show other perspective.
\end{abstract}

Keywords: Constitutionalization. Personality rights. Physical integrity. Right to quietness. Jurisprudence.

\section{INTRODUÇÃ̃O}

\footnotetext{
${ }^{1}$ Mestrando em Ciência Jurídica pela Universidade Estadual do Norte do Paraná (UENP), bacharel em direito pela Faculdade de Direito de Ribeirão Preto da Universidade de São Paulo (FDRP-USP), coordenador do Grupo de Pesquisa Responsabilidade Internacional do Estado e Direitos Humanos (UENP). E-mail: contatoaguilar@gmail.com.
} 
A evolução das relações sociais caminha em paralelo com o desenvolvimento teórico e jurisprudencial do direito privado como um todo e, mais especificamente, com os direitos da personalidade.

Antes relacionados ao reconhecimento de direitos básicos naturais e, portanto, inatos ao homem, como a vida e a liberdade, hoje os direitos da personalidade integram discussões onde a não compreensão das dinâmicas entre biotecnologia, comunicação e mercado pode prejudicar sua teorização e alcance. Mais importante, porém, que a compreensão de conceitos científicos, é captar a relação entre o princípio da dignidade humana, balizador de todo o sistema jurídico brasileiro, nessa heterogeneidade de direitos da personalidade consequente do seu livre desenvolvimento.

A reordenação de um sistema jurídico essencialmente privatista, individualista e formal, para um sistema nucleado no princípio da dignidade humana e materializado em direitos fundamentais, pode estimular o livre desenvolvimento da personalidade, desde que alcance uma teoria jurídica não alienada e uma atuação jurisprudencial sensível à garantia desse livre desenvolvimento pessoal. A constitucionalização do direito civil, ao permitir o preenchimento de lacunas seguindo a axiologia dos direitos fundamentais realizadores da dignidade humana, será fenômeno de grande importância para garantir esse desenvolvimento.

É o caso do desenvolvimento do direito ao sossego como direito da personalidade, cujo amadurecimento e reflexão ao princípio da dignidade passa necessariamente pela observação da natureza e significado do direito à integridade física como direito que orbita um sistema jurídico repersonalizado e ressignificado pela constitucionalização do direito civil e o papel da dignidade da pessoa humana.

Desta forma, considerando o fenômeno da Constitucionalização do Direito Civil e o conceito de direito à integridade física inserido nos direitos da personalidade, objetiva-se delinear o conceito e aplicação do direito ao sossego na perspectiva do direito à integridade física. Para tanto, procede-se ao estudo exploratório de fontes secundárias e primárias, aplicando-se aos dados obtidos o raciocínio indutivo, permitindo concluir que a atuação jurisprudencial vem focando numa aplicação do direito ao sossego marcada pela perspectiva do direito à honra, quando o estudo e conceituação do direito à integridade física permitem perfeitamente atribuir esta perspectiva à aplicação do direito ao sossego.

\section{DIREITOS DA PERSONALIDADE E DIGNIDADE HUMANA}

Revista Brasileira de Direito Civil em Perspectiva | e-ISSN: 2526-0243| Porto Alegre | v. 4 | n. 2 |

p. 62 - 78 | Jul/Dez. 2018 
Os direitos que integram a personalidade do indivíduo carregam características específicas segundo sua natureza e são conferidos à pessoa humana dentro de seus aspectos e valores íntimos como também em sua projeção exterior. Pode-se dizer que os direitos da personalidade têm como objeto a própria pessoa (HEINZMANN; FACHIN, 2010, p.220) ou os aspectos que formam a pessoa, e não encontram correspondência com valores pecuniários (PEREIRA, 1995, p.6-7), mas com direitos essenciais ao livre desenvolvimento pessoal como, por exemplo, o direito à própria vida, ao corpo e sua integridade física - bem como direitos essenciais ao reconhecimento dessa personalidade na sociedade em que ela se encontra, como os direito à honra, à intelectualidade, à intimidade, ao segredo, à identidade e à moral, entre outros.

Essa definição encontra respaldo em Bittar (2015, p.29), segundo o qual os direitos da personalidade são aqueles "reconhecidos à pessoa humana tomada em si mesma e em suas projeções na sociedade, previstos no ordenamento jurídico exatamente para a defesa de valores inatos no homem".

Uma das razões de se vincular os direitos da personalidade não só àqueles essencialmente pessoais, como a vida e o corpo, como também àqueles referente à projeção da pessoa humana na sociedade, remete ao interesse coletivo que orbita os objetivos pessoas que cada um possui em sua vida. Enquanto, de um lado, é interesse da pessoa não ficar doente, salvaguardando sua integridade física, é interesse do Estado, fundado na regra básica de convivência, que a pessoa desenvolva suas aptidões, contribuindo para o progresso coletivo (BITTAR, 2015, p.129-130).

Uma segunda razão encontra respaldo na proteção devida pelo Estado diante do seu domínio sobre as individualidade visto que houve uma disposição dessa liberdade individual a partir de um Contrato Social teorizado por Rousseau e que, como se verá adiante, influenciou a formulação dos direitos da personalidade dentro de um sistema de leis.

Como as entidades de pessoa jurídica são detentoras de direitos e obrigações e recebem a atribuição de personalidade jurídica, Morato (2011, p.124, grifos do autor) defende a definição dos direitos da personalidade como aqueles que "versam sobre a própria pessoa e seus reflexos e que são reconhecidos à pessoa humana e atribuídos à pessoa jurídica.” 
Uma vez reconhecidos à pessoa humana, os direitos da personalidade permitem sua defesa contra a ameaça externa, seja do Estado, seja de terceiros. Essa "permissão" traduz a própria definição dos direitos da personalidade para Diniz (2005, p.123), segundo a qual “o direito de personalidade é o direito da pessoa de defender o que lhe é próprio, como a vida, a identidade, a liberdade, a imagem, a privacidade, a honra, etc."

$\mathrm{O}$ direito de se exigir comportamento negativo de todos, inclusive do Estado (NAGEL, 1995, p.84), relaciona-se aos chamadas direitos de liberdade, caracterizados por este comportamento, que se traduz na não interferência nestes direitos (MORATO, 2011, p.137-138).

Embora considerados como projeção dos direitos naturais (PEREIRA, 1995, p.5), uma vez que os direitos da personalidade versam sobre as características que constituem seus valores mais íntimos, é notável que se trata de uma teoria de construção recente, marcada principalmente pelo seu reconhecimento frente ao Estado através das codificações, principalmente a partir do século XVIII, sob influência da teoria contratualista de Rousseau, apesar da Magna Carta inglesa reconhecer direitos próprios do ente humano já no século XIII (BITTAR, 2015, p.51).

Dessa relação entre a teoria contratualista de Rousseau e a atuação dos jus-filósofos do século XVIII é que nasce a Constituição norte-americana de 1787 e a Declaração de Direitos do Homem e do Cidadão de 1791, textos que marcam o reconhecimento de direitos inatos ao homem (BITTAR, 2015, p.130) mesmo sendo possível, como mencionado, encontrar direitos próprios do ente humano já no século XIII ou antes disso.

O fundamento do Direito Natural atribuído aos direitos da personalidade sustenta uma importante característica sua, que é a impossibilidade de normatizá-los em um rol taxativo de direitos (BITTAR, 2015, p.141). Essa natureza ganha relevância quando se observa que a evolução dos direitos da personalidade está diretamente ligada à evolução da sociedade, da tecnologia e da medicina, podendo-se mencionar, apenas a título de exemplificação, as questões vinculadas à identidade de gênero e nome social, os direitos autorais e os meios de comunicação, a imagem de pessoas jurídicas e produtos comerciais e o contexto jurídico em que se inserem os embriões e a fertilização in vitro - situações inimagináveis no século XVIII, quando as notadas codificações anteriormente mencionadas foram criadas, ou mesmo no começo do século XX, quando o mundo começava a entender os

Revista Brasileira de Direito Civil em Perspectiva | e-ISSN: 2526-0243| Porto Alegre | v. 4 | n. 2 |

p. $62-78$ | Jul/Dez. 2018 
reflexos - jurídicos e ambientais - da revolução industrial. Neste sentido, Bolson (2004, p.138, grifos da autora) sustenta que

\begin{abstract}
se o valor fundamental do ordenamento jurídico, hoje, é a pessoa humana e sua dignidade, parece-nos que enclausurar os direito da personalidade em um rol fechado não é a melhor opção legislativa. [...] Quando, no século XIX, se imaginaria que um contratante poderia requerer a revisão das cláusulas de um contrato - direito do consumidor à revisão dos contratos? Ou que um fornecedor poderia ser responsabilizado por anotação indevida em cadastro de crédito - direito do consumidor a um nome sem mácula? Ou mesmo que um fabricante de cigarro seria responsabilizado pelos danos à saúde do fumante - direito do consumidor à saúde e qualidade do produto? Sem falarmos dos interesses existentes relacionados ao Biodireito e à Bioética, os quais já são objetos de intensos debates, como é o caso do clone humano [...]
\end{abstract}

Como se observa, a existência de uma dignidade humana como valor fundamental do ordenamento, e que deve ser tutelado, poderá suprir a positivação taxativa (e impossível) desses direitos da personalidade na busca por uma proteção suficiente do Estado sobre estes direitos e realização de efetiva justiça. Assim, supera-se o debate sobre a tipicidade e individuação dos direitos da personalidade quando se reconhece a positiva interferência das normas constitucionais sobre os institutos do direito civil (HOLANDA, 2017, p.40), reconhecimento este que passa pela adoção da tese naturalista já mencionada.

Inegável, porém, que a positivação impulsiona a construção teórica dos direitos da personalidade e seu reconhecimento pela ordem jurídica permite atribuir aos direitos da personalidade características de direito subjetivo, ou seja, de um interesse juridicamente protegido (PEREIRA, 1995, p.8). Por outro lado, embora o reconhecimento destes direitos na legislação constitucional ou infraconstitucional delimite seu campo de estudo e atribuem-lhes status fundamental ou infraconstitucional, é importante salientar que eles não restringem os direitos da personalidade apenas àqueles reconhecidos no ordenamento jurídico, uma vez que são inerentes ao próprio ser humano e existem antes mesmo de sua positivação (BITTAR, 2015, p.38-39).

Ganha relevância essa instituição de mecanismos de proteção quando se observa que a evolução social e tecnológica passa a exigir mais do Estado em termos de regulamentação e tutela. Os exemplos antes contemplados, como a identidade de gênero, direito autorais, imagem de pessoas jurídicas e novos meios de fertilização in vitro, demonstram a incapacidade de se ter um rol taxativo de direitos da personalidade, como reforçam a 
importância da atuação jurisprudencial no reconhecimento desses direitos a fim de tutelar, respectivamente, a possibilidade de uso de nome social, a ameaça da internet aos direitos autorais e à imagem de pessoas jurídicas e a seleção genética indiscriminada e com ideais meramente estéticos.

O progresso biotecnológico coloca o organismo humano como objeto de novos tipos intervenção que alcançam o nível mais profundo do substrato orgânico que influencia a própria autocompreensão dos seres humanos (HABERMAS, 2004, p.17-18). Trata-se da ressignificação da condição humana a partir de técnicas que, à primeira vista, surgiram para proporcionar maior autonomia ao indivíduo, agora capaz de forjar sua existência através de drogas, peças de reposição do corpo, técnicas de reprodução assistida e promessas de clonagem (ALEKSANDROWICZ; MINAYO, 2005, p.518).

Esses avanços capazes de levantar questionamentos éticos, porém, não se restringem ao progresso médico e científico: as grandes guerras perpetradas no século XX colocaram em xeque o poder estatal ilimitado fundado na vontade e consentimento das maiorias (ASCENSÃO, 2006, p.146), enquanto o hiperconsumo e massificação dos contratos impões desafios na regulação das relações de consumo. Tudo isso se insere numa realidade marcada pela variedade de soluções que o pluralismo religioso, moral e jurídico fornece aos conflitos entre o Estado e seus cidadãos ou entre os particulares (LIMA, 2011, p.160).

Assim, é possível observar que o reconhecimento dos direitos da personalidade não é importante apenas entre aqueles considerados "sofisticados". Direitos básicos como a liberdade, a vida e a integridade física merecem respaldo legal quando constantemente ameaçados por regimes autoritários ou sob a bandeira de proteção da coletividade, uma vez que seu reconhecimento, seja legal ou jurisprudencial, permite a criação de instituições destinadas à reforçá-los.

\section{CONSTITUCIONALIZAÇÃO DO DIREITO CIVIL}

A Constituição Federal de 1988 (CF/1988) apresenta vasto elenco de direitos da personalidade e sua tutela; ou outros direitos que, se não se inscrevem como direitos da personalidade inatos, podem ser considerados como adquiridos ou concedidos pela constituição, enumerados principalmente em seu artigo $5^{\circ}$.

O reconhecimento e tutela dos direitos da personalidade pela lei fundamental esboça que a percepção da autonomia do direito privado é restrita por aquela dentro da estrutura do 
ordenamento jurídico. Ora, se por um lado os direitos da personalidade são absolutos e oponíveis erga omnes, é flagrante que a soberania popular também insere-se no reconhecimento dos direitos fundamentais. Por essa razão Fachin (2015, p.64) mencionará que

a autonomia privada mantém relação com a soberania popular, e simultaneamente, significa uma relação de complementação recíproca, pois o direito à autodeterminação também constitui direito humano. A eficácia externa imediata da lei fundamental significa que a dignidade humana deve ser respeitada não somente por medidas do estado, mas também por ações dos sujeitos privados, com relação à integridade física e ao núcleo absoluto da personalidade.

A maior contribuição da $\mathrm{CF} / 1988$ aos direitos da personalidade não se encontra porém, no seu reconhecimento extenso dentro dos direitos fundamentais assegurados no art. $5^{\circ}$ da mesma e que supera a disciplina do próprio Código Civil de 2002 (CC/2002), mas na posição que ocupa como fundamento de um ordenamento jurídico que terá na dignidade humana sua expressão maior de valor primordial e indispensável. Neste novo Direito Civil, agora conectado de forma simpática ao Direito Constitucional,

além da estrutura centrada em princípios e cláusulas abertas, os direitos da personalidade estão balizados não somente por um franco, explícito e declarado rol não taxativo de direitos reconhecidos pelo traçado que lhes foi conferido pelo projeto do Código Civil de Miguel Real, mas também por uma fundamentação que decorre da Constituição Federal de 1988, em seu art. 1", III: "a dignidade da pessoa humana". Este princípio serve, nesse sentido, como bússola do sistema jurídico como um todo, e, nestes termos, serve de fundamento a unificar o tratamento da matéria, não importando a perspectiva na qual se abordem esses direitos, e muito menos a ramificação do direito à qual se esteja a reportar.(BITTAR, 2015, p.36, grifos do autor).

De fundamento do ordenamento jurídico insculpido no art. $1^{\circ}$, III da CF/1988, até a efetiva atuação como bússola do sistema jurídico, como um todo, e atuação nos direitos da personalidade, especificamente, a dignidade humana precisa superar o exercício intelectual que a coloca como conceito transcendental para finalmente permear a atuação jurisprudencial ao lado de uma construção teórica que contemple o franco processo de desenvolvimento social e tecnológico. Se reconhecimento, porém, esboça uma incidência de valores e 
princípios constitucionais no Direito Civil que "reflete a preocupação em edificar uma ordem jurídica voltada aos demandantes problemas e desafios da sociedade contemporânea" (FACHIN, 2015, p.62).

A dignidade é qualidade imutável e perene (ou perpétua), essencial (ou inerente) à vida humana. Ela não pode ser acrescentada, ou diminuída, mas pode certamente ser violada (RIBEIRO, 2014, p.864). Em oposição a este conceito ontológico, cuja premissa reconhece uma igual dignidade a todo ser humano, a vida em sociedade atribui uma concepção intersubjetiva da dignidade na qual todos passa a ser credores e devedores de uma igual proteção perante o Estado através do exercício recíproco do direito à dignidade (RIBEIRO, 2014, p.865), de forma que apenas a tutela intervencionista do Estado pode garantir essa igual proteção, ou seja, apenas com o imperium característico ao direito público e à hierarquia das normas é que o direito privado poderia realizar a igualdade como ideal do justo (MARQUES; MIRAGEM, 2014, p.129-130).

Esse caminho, de uma concepção universal da dignidade humana, até seu reconhecimento numa relação entre dois indivíduos ou entre um indivíduo e o Estado, fornece substrato à delimitação da dignidade humana na materialização de direitos que permitam evitar a redução ou descaracterização do ser humano - de sujeito de direitos a mero objeto -, uma efetivação necessária quando o sujeito não encontra-se solado, mas sim contextualizado à vida social.

Realizar a materialização da dignidade humana nos direitos da personalidade e “pincelar" aqueles essenciais não é possível quando todos são essenciais ao livre e digno desenvolvimento da pessoa, mas o simples reconhecimento da necessária dignidade humana e sua garantia demonstra a ascensão de nova perspectiva jurídica privatista, um deslocamento do núcleo patrimonial em direção ao reconhecimento da personalidade, ou seja, uma repersonalização dos direitos privados estimulada pela advento da Constituição Federal de 1988 e seu postulado fundamental (HOLANDA, 2017, p.40) que permitiram a colocação da pessoa como fundamento das relações civis, posição antes ocupada pelo patrimônio (MORAES, M., 2006, p.120; HOLANDA, 2017, p.40).

A partir de então, passa-se a ser difícil conceber um interesse privado completamente autônomo, isolado do interesse público (FACHIN, 2015, p.62), razão pela qual pode-se falar na identificação de um direito civil identificado como espécie de direito constitucional da pessoa, afetando não só a propriedade, família, a criação e a proteção da infância e juventude 
(MIRAGEM, 2013, p.46-48), como os desenvolvimento dos direitos da personalidade através de sua disciplina constitucional exaustiva que estimulará uma atuação judiciária afeita ao seu livre desenvolvimento - algo incapaz quando a própria liberdade violava a liberdade para desenvolver sua personalidade.

Este fenômeno de repersonalização insere-se na ocorrência da constitucionalização do direito civil que concretizou a elevação dos princípios fundamentais do direito civil ao plano constitucional, condicionando, assim, a aplicação da legislação infraconstitucional à observação destes princípio, tanto pelas relações entre cidadãos como pela aplicação dos tribunais (LÔBO, 1999, p.100): o polissistema legal - formado pela proliferação de legislações esparsas e estatutos especializados - encontra, agora, uma unidade sistemática e axiológica na Constituição Federal (MORAES, M. 2006, p.234), com repercussão em institutos antes marcados pelo patrimonialismo e individualismo, como a liberdade individual, a liberdade contratual, a responsabilidade civil, a propriedade, a possa e a herança, chegando, finalmente, nos direito da personalidade, que recebem o influxo dos direitos fundamentais e a reação do sujeito perante o Estado (FACHIN, 2015, p.38-39).

O dinamismo que permeia o conceito de pessoa, descrito a partir das ideias de autonomia, intersubjetividade e individualidade (SILVA, 2014, p.60) e que impõe ao Estado reconhecê-los, não lista-los, já marcado pela superação da individuação dos direitos da personalidade pela adoção da tese naturalista, encontra, no fenômeno da constitucionalização do direito civil, um reforço voltado à interpretação a partir da avaliação condizente entre princípios jurídicos e valoração destes dentro do sistema jurídico (MORAES, M. 2006, p.234).

Assim, nos direitos da personalidade, a concepção naturalista que "permite reconhecer a existência de direitos da personalidade não tipificados pelo ordenamento jurídico" (HOLANDA, 2017, p.43), encontra na constitucionalização do direito civil a imposição da observação centrada no princípio da dignidade humana, alcançando a coletividade que apoia direitos como a liberdade, a vida e a integridade física diferente daquela que os ameaça através do suporte ao totalitarismo.

\section{DIREITO AO SOSSEgO NA PERSPECTIVA DO DIREITO À INTEGRIDADE FÍSICA}

Revista Brasileira de Direito Civil em Perspectiva | e-ISSN: 2526-0243| Porto Alegre | v. 4 | n. 2 |

p. $62-78$ | Jul/Dez. 2018 
O direito ao próprio corpo é um instituto que, assim como o direito civil como um todo, viu sua proteção se dirigir de um caráter eminentemente patrimonialista para aquele pessoal e coletivo que permeia os direitos da personalidade atualmente.

Assim, enquanto antes a disposição do próprio corpo assumia a perspectiva do direito da propriedade, relacionando-se à liberdade de fruir e dispor dentro dos limites impostos pela comunidade (SILVA, 2014, p.64-65), sua indisponibilidade fora relativizada no mesmo caminho que relativizou-se a ideia de bons-costumes, abarcando não só os transplantes de órgãos, como a possibilidade de cirurgia de redefinição sexual (SILVA, 2014, p.66), ou a modificação corporal sem caráter médico, o bodymodification. Trata-se de uma reinterpretação do artigo 13 do Código Civil de 2002 para acompanhar a evolução social e médica mas também a centralização da dignidade humana no ordenamento e, consequentemente, a proteção da autonomia uma vez que, segundo Aleksandrowicz e Minayo (2005, p.520), é a "capacidade dos homens de se darem os seus próprios fins" que funda "a possibilidade de liberdade, na concepção da filosofia kantiana”.

O direito ao próprio corpo pode ser visto tanto do ponto de vista da autonomia corporal, marcada pelo exercício da autonomia sobre o que fazer com o próprio corpo (HERRING; WALL, 2017, p.568), como do ponto de vista do direito à integridade física, considerado como a proteção contra intocabilidade do corpo físico e mental da pessoa (HOLANDA, 2017, p.49).

Os artigos 13 e 14 do CC/2002 preconizam sobre a disposição de partes do corpo, em vida ou após a morte, desde que, quando em vida, esta não importe em diminuição permanente da integridade física ou contrarie os bons costumes. Já o artigo 15 do código reforça a autonomia pessoal do paciente nos casos de tratamento médico ou intervenção cirúrgica.

O Código Penal, por sua vez, ao punir o homicídio (art. 121), o feminicídio (art. 121, VI), o induzimento ao suicídio (art. 122), o infanticídio (art. 123) e o aborto (arts. 124 a 127); além da lesão corporal (art. 129), a lesão corporal seguida de morte (art. 129, § $3^{\circ}$ ), a lesão corporal culposa (art. 129, § $6^{\circ}$ ) e a violência doméstica (art. 129, § $9^{\circ}$ ), desenvolve arcabouço jurídico penal de tutela da integridade física e da vida.

Trata-se de uma proteção dos direitos da personalidade cuja importância reflete sua presença em ambos os códigos e não seria diferente quando o corpo media as percepções com o mundo e a vinculação com ele, a formulação de nossas preferências, valores e fundamentos, 
ou seja, estados relevantes subjacentes à moral se integram ao corpo e não existiriam sem ele (HERRIG; WALL, 2017, p.579-580). O entendimento de Herring e Wall (2017, p.580, tradução nossa) sobre o princípio da integridade física é esclarecedor neste sentido:

Podemos, portanto, construir uma concepção do direito à integridade física
que não seja redutível ao princípio da autonomia. O direito dá a uma pessoa
o uso e controle exclusivo de seu corpo com base em que o corpo é o local, a
localização ou o ponto focal de sua subjetividade (embora compreendido e
constituído). É porque o corpo é onde nós experimentamos estados de bem-
estar, é o local onde nós florescermos como humanos, é o meio pelo qual nós
interagimos com os outros, e é a maneira pela qual nós executamos nosso
agir, que temos um direito tão amplo e abrangente sobre nossos próprios
corpos.

O corpo media a interação entre subjetividade e o mundo, essa é a premissa comum às diferentes explicações para a exclusividade no controle do corpo e o dever de respeitar o direito exclusivo das pessoas no controle e uso de seus corpos (WALL, 2015, p. 41). Esse dever de respeito concorda com a fundamentação kantiana de racionalidade e livre arbítrio que sustenta a dignidade humana e que se conforma através da manutenção da liberdade, da igualdade, da solidariedade e da integridade psicofísica da pessoa humana (MORAES, M. 2006, p. 358).

A correspondência substancial entre o direito à integridade física e o princípio da dignidade humana - impulsionada a partir do fenômeno da constitucionalização do direito civil e em particular dos direitos da personalidade -, fora responsável pela transformação da responsabilidade civil de um instituto caracteristicamente focado na proteção da propriedade através da punição, para um modelo de prevenção e abrigo da dignidade da pessoa humana.

Essa transformação da responsabilidade civil permitiu o reconhecimento da ocorrência de aflição psicológica em violações contratuais de consumo, especialmente aqueles correspondentes ao fornecimento de produtos cativos e de longa duração, bem como na constatação de ocorrência de danos morais em relações paternais quando em jogo a integridade psicofísica dos menores de idade (MORAES, M. 2006, p.247-248).

A mesma correspondência substancial se observa agora na formulação do direito ao sossego a partir da proteção à integridade física e psíquica.

Assim como os direitos à integridade física e à vida, o direito ao sossego também não é novidade no direito penal, no qual a perturbação do trabalho ou sossego alheios se vê 
prevista no art. 42 do Decreto-lei n. 3688, de 3 de outubro de 1941 (Lei de Contravenções Penais), enquanto a produção de poluição de qualquer natureza capaz de causar danos à saúde humana encontra-se prevista no art. 54 da Lei n. 9.605, de 12 de fevereiro de 1998, que dispõe sobre sanções penais e administrativas derivadas de condutas lesivas ao meio ambiente. No segundo caso, a poluição sonora caracteriza-se como forma de poluição principalmente por sua capacidade de causar danos ao ambiente humano.

No tocante aos conflitos de vizinhança, o Código Civil de 2002 também prevê, em seu art. 1.277, a possibilidade do proprietário ou possuidor de um prédio fazer cessar as interferências prejudiciais à segurança, ao sossego e à saúde dos que o habitam, pela utilização de propriedade vizinha.

A atuação da doutrina e jurisprudência, por outro lado, atribui nova visão ao direito ao sossego ao relacioná-lo como necessário à manutenção da integridade física e psicológica, mais um exemplo de como a constitucionalização do direito civil permite reforçar a interpretação a partir da avaliação condizente entre princípios jurídicos e valoração destes dentro do sistema jurídico.

Loureiro (2004, p.117), estudando o tema, apontou a presença de direitos elencados no art. $5^{\circ}$ da Constituição Federal de 1988 como garantidores do direito ao sossego uma vez que asseguram a tranquilidade e a ausência de preocupações à pessoa. Entre estes direitos estariam o direito à vida (art. $\left.5^{\circ}, c a p u t\right)$, à intimidade (art. $\left.5^{\circ}, \mathrm{XI}\right)$, à inviolabilidade do sigilo de correspondência, das comunicações telegráficas, de dados e das comunicações telefônicas (art. $\left.5^{\circ}, \mathrm{XII}\right)$ e à livre locomoção (art. $\left.5^{\circ}, \mathrm{XV}\right)$.

A atuação do Tribunal de Justiça de São Paulo (TJ-SP) vem reconhecendo a violação do direito ao sossego em demandas cíveis, especialmente violações de contratos de consumo.

É o caso, por exemplo, de consumidor compelido a reiterar mensalmente via atendimento telefônico de fornecedora de serviço de tv a cabo o cancelamento de cobrança indevida realizada após pedido de cancelamento do serviço. Enquanto não houve inclusão indevida em órgãos de proteção ao crédito, o que ensejaria um pedido de dano moral por ofensa à honra do consumidor, a necessidade mensal de pedir via contato telefônico o cancelamento de fatura inexistente, repetida no período de um ano, também motiva a reparação por conta da violação do direito ao sossego (SÃO PAULO, 2016a).

Em situação análoga, manifestou-se na mesma direção o tribunal ao observar que "os protocolos de ligação [...], a nosso ver ultrapassam em muito, mero dissabor do cotidiano, 
tendo o comportamento adotado pela apelada atingido, sobremaneira, a paz, o sossego e a tranquilidade do consumidor" (SÃO PAULO, 2016b, grifo nosso), enquanto a mesma fundamentação se coloca à disposição na proteção de consumidor que não teve a garantia do produto obedecida mesmo após inúmeros contatos telefônicos:

Dito de outro modo, por consequência da falha havida, o autor se viu na contingência de enfrentar verdadeira maratona, durante mais de um ano, na tentativa de contatar o réu e ver solucionado seu problema, pelo conhecido serviço de telemarketing, sempre de forma inexitosa. Logo, mais que mero aborrecimento, caracterizado o dano moral, que está in re ipsa, ou seja, está na própria conduta de violação de direito da personalidade, no caso o direito ao sossego e tranquilidade do autor. (SÃO PAULO, 2013).

Em comum, as fundamentações expostas demonstram uma aplicação do direito ao sossego compreendido como a garantia de se manter a paz de espírito ou tranquilidade na formulação de contratos de consumo. Essa interpretação abarca uma perspectiva que, em um primeiro momento, demonstra uma aplicação deste direito no sentido de proteção e preservação da integridade moral do consumidor.

Essa distinção, que vincula a paz de espírito à moral e à honra, ou seja, que assimila o direito ao sossego à integridade moral do indivíduo, afasta a relação entre ansiedade e estresse com o local onde de fato elas ocorrem: a mente humana, espaço do corpo onde se constroem as concepções de mundo e interações sociais que de fato exercerão o florescer como humano e a aplicação de toda autonomia e respeito ao corpo que condiz com o cumprimento da dignidade da pessoa humana.

O reconhecimento do corpo como mediador da interação entre subjetividade e o mundo permite trazer um pouco de objetividade à interpretação de valores subjetivos em demandas cíveis que envolvam o direito ao sossego, ou seja, possibilita manter correspondência substancial entre o direito à integridade física e o princípio da dignidade humana muito antes de se supor uma ofensa à honra sustentada como dano presumido. Nas palavras de Loureiro (2004, p.117),

[...] o que se busca é não só o aspecto físico mas também o psíquico, que lhe é indissociável, incluídas as funções intermédias do corpo. Por isso, pode-se afirmar ser o sossego um dos direitos de personalidade, na medida em que diz respeito ao desenvolvimento da saúde físicopsíquica do homem. 
Direitos não são autoevidentes, requerem argumentos, definições e ajustes precisos. Quando esses ajustes concretizam - como no caso da constitucionalização do direito civil e seus efeitos sobre os direitos da personalidade -, um status jurídico insere seus tutelados numa comunidade moral onde vigora a projeção do direito constitucional no direito civil através do valor dado aos princípios jurídicos.

Nesse processo dinâmico, onde o código não nasce pronto, mas se faz, afrontam-se fronteiras e lacunas antes existentes (FACHIN, 2015, p.56) para um direito da personalidade sustentado no princípio da dignidade humana e sua materialização em direitos fundamentais: os direitos humanos se traduzem em exigências de direitos fundamentais; os direitos fundamentais se traduzem em direitos da personalidade; os direitos da personalidade, por sua vez, integram o ordenamento jurídico e tornam-se suscetíveis de mais elevadas exigências, não apenas do seu reconhecimento (FACHIN, 2015, 23).

A integração dos direitos da personalidade à atuação jurisprudencial e sua exigência cada vez mais elevada daqueles que integram a comunidade moral tutelada fornecerá, futuramente, a materialização de um princípio da dignidade humana no tocante aos direitos da personalidade, em harmonia com uma sociedade e ciência em constante evolução. A compreensão da natureza e significação do corpo humano e, consequentemente, do direito à integridade física, colaboram para o amadurecimento dessa atuação no sentido de desenvolver e balizar o direito ao sossego na perspectiva da integridade física.

\section{CONSIDERAÇÕES FINAIS}

Da massificação dos contratos à grandes guerras, a ascensão de uma sociedade da informação e, hoje o excesso de informação, o direito civil passou por diferentes mudanças e reordenações. Da mesma forma, a dignidade humana viu transformar-se de conceito ligado ao pecado e religiosidade, à secularização promovida por Kant e as discussões acerca do seu papel dentro de um status moral e sua inviolabilidade mesmo em nome da coletividade.

Enquanto a teoria jurídica justifica e realça as alterações nas relações intersubjetivas e estatais, a tecnologia disseca possibilidades inimagináveis sequer no pós-guerra, permitindo a clonagem, redesignação sexual, desintegração de direitos autorais em segundos; todos estes, temas relacionados ao direito da personalidade, direito natural de teoria recente justamente porque envolve conflitos morais recentes.

Revista Brasileira de Direito Civil em Perspectiva | e-ISSN: 2526-0243| Porto Alegre | v. 4 | n. 2 |

p. 62 - 78 | Jul/Dez. 2018 
Recorrer à dignidade humana como bússola de um ordenamento jurídico que encara tantas e tão velozes transformações, indica recorrer ao império do direito e à coação estatal não para minar interesses individuais, mas para garantir que estes se desenvolvam de acordo com uma ordem vigente e uma coletividade a fim de manter sua igualdade substancial.

No campo dos direitos da personalidade, o realinhamento do direito civil em conformidade com o princípio da dignidade humana, fenômeno reconhecido como constitucionalização do direito civil, colabora com a manutenção dessa igualdade substancial e garante que a liberdade não interfira no livre desenvolvimento da personalidade, ou seja, que a atuação judiciária permita a concretização de direitos da personalidade não taxados nas codificações e multifacetados justamente porque assim o permite a cláusula geral de proteção e o fundamento de uma vida digna, igual e livre.

Exemplo dessa possibilidade de livre desenvolvimento de direitos da personalidade encontra-se na formulação e aplicação do direito ao sossego em demandas cíveis e consumeristas.

Sua inserção nos direitos da personalidade atribuem-lhe perspectiva da proteção da honra e da proteção da integridade física. No segundo caso, reconhecer a natureza e significado deste direito da personalidade colabora para desenvolver outro direito da personalidade, agora sem origem codificadora mas perfeitamente compreensível deste ponto de vista e balizado pelo fenômeno da constitucionalização do direito civil: o direito ao sossego.

\section{REFERÊNCIAS}

ALEKSANDROWICZ, Ana Maria C.; MINAYO, Maria Cecília de Souza. Humanismo, liberdade e necessidade: compreensão dos hiatos cognitivos entre ciências da natureza e ética. Ciência e Saúde Coletiva, Rio de Janeiro, v. 10, n. 3, p. 513-526, 2005.

ASCENSÃO, José de Oliveira. Pessoa, direitos fundamentais e direito da personalidade. Revista de Mestrado em Direito, Osasco, v. 6, n. 1, p. 145-168, 2006.

BITTAR, Carlos Alberto. Os direitos da personalidade. 8. ed. São Paulo: Saraiva, 2015.

BOLSON, Simone Hegele. Direitos da personalidade do consumidor e a cláusula geral de tutela da dignidade da pessoa humana. Revista de Direito do Consumidor. São Paulo, v. 52, p. 130-162, out./dez. 2004.

Revista Brasileira de Direito Civil em Perspectiva | e-ISSN: 2526-0243| Porto Alegre | v. 4 | n. 2 |

p. 62 - 78 | Jul/Dez. 2018 
DINIZ, Maria Helena. Curso de direito civil brasileiro: teoria geral do direito civil. 22. ed. São Paulo: Saraiva, 2005.

FACHIN, Luiz Edson. Direito civil: sentidos, transformações e fim. Rio de Janeiro: Renovar, 2015 .

HABERMAS, Jürgen. O futuro da natureza humana: a caminho de uma eugenia liberal? Tradução Karina Jannini. 1. ed. São Paulo: Martins Fontes, 2004.

HEINZMANN, Clara; FACHIN, Zulmar. Os direitos da personalidade como direitos subjetivos públicos. Revista Jurídica Cesumar - Mestrado, Maringá, v. 10, n. 1, p. 217-234, jan./jun. 2010.

HERRING, Jonathan; WALL, Jesse. The nature and significance of the right to bodily integrity. Cambridge Law Journal. v.76, n.3, p. 566-588, nov. 2017.

HOLANDA, Danielle Spencer. A repercussão da constitucionalização sobre os direitos da personalidade: em busca da dignidade da pessoa humana. Revista Eletrônica da Faculdade de Direito de Franca, Franca, v. 12, n. 2, p. 37-64, dez. 2017.

LIMA, Cíntia Rosa Pereira de. O valor do corpo e as leis de mercado. Revista da Faculdade de Direito da Universidade de São Paulo, São Paulo, v. 106/107, p. 159-178, jan./dez. 2011/2012.

LÔBO, Paulo Luiz Netto. Constitucionalização do direito civil. Revista de Informação Legislativa, Brasília. v. 36, n. 141, p. 99-109, jan./mar. 1999.

LOUREIRO, Francisco Eduardo. Direito ao Sossego. In: LOTUFO, Renan (coo.). Cadernos de Direito civil constitucional: caderno 2. Curitiba: Juruá, 2004.

MARQUES, Cláudia Lima; MIRAGEM, Bruno. O novo direito privado e a proteção dos vulneráveis. 2. ed. São Paulo: Editora Revista dos Tribunais, 2014.

MIRAGEM, Bruno. Curso de Direito do Consumidor. 4. ed. São Paulo: Editora Revista dos Tribunais, 2013.

MORAES, Maria Celina Bodin de. A constitucionalização do direito civil e seus efeitos sobre a responsabilidade civil. Direito, Estado e Sociedade, Rio de Janeiro, v. 9, n. 29, p. 233-258, jul./dez. 2006.

MORAES, Paulo Valério Dal Pai. Compatibilidade entre os princípios do código de defesa do consumidor e os do novo código civil. Revista de Direito do Consumidor, v. 57, p. 77-128, 2006.

Revista Brasileira de Direito Civil em Perspectiva | e-ISSN: 2526-0243| Porto Alegre | v. 4 | n. 2

p. 62 - 78 | Jul/Dez. 2018 
MORATO, Antonio Carlos. Quadro geral dos diretos da personalidade. Revista da Faculdade de Direito da Universidade de São Paulo. São Paulo, v. 106/107, p. 121-158, jan./dez. 2011/2012.

NAGEL, Thomas. Personal Rights and Public Space. Philosophy and Public Affairs, Princeton, vol. 24, n. 2, p. 83-107, spring, 1995.

PEREIRA, Caio Mário da Silva. Direitos da personalidade. Revista Pensar, Fortaleza, v. 3, n. 3, p. 5-19, jan. 1995.

RIBEIRO, Wesllay Carlos. As modernas relações entre direito civil e direito constitucional: a tutela da pessoa em foco. Revista Pensar, Fortaleza, v. 19, n. 3, p. 859-886, set./dez. 2014.

SÃO PAULO. TJ-SP, Apelação n. 1026135-65.2014.8.26.0576, 12 $2^{\text {a }}$ Câmara Extraordinária de Direito Privado, Rel. Des. Ramon Mateo Júnior, j. 15-04-2016.

TJ-SP, Apelação $n^{o}$ 0008319-95.2013.8.26.0132, 12 $2^{\mathrm{a}}$ Câmara Extraordinária de Direito Privado, Rel. Des. Ramon Mateo Júnior, j. 14-09-2016.

TJ-SP, Apelação n. 0133239-56.2007.8.26.0002, $1^{\text {a }}$ Câmara de Direito Privado, Rel.

Des. Claudio Godoy, j. 2-07-2013.

SILVA, Denis Franco. Live uso do corpo e direitos de personalidade. Revista Pensar, Fortaleza, v. 19, n. 1, p. 56-70, jan./abr. 2014.

WALL, Jesse. Being and owning: the body, bodily material, and the law. Oxford: Oxford University Press, 2015. 